\title{
EL TURISMO RELIGIOSO EN DISTINTAS ZONAS GEOGRÁFICAS DE ESPAÑA: CARACTERÍSTICAS DE LOS TURISTAS
}

\author{
Genoveva Millán Vázquez de la Torre \\ Departamento de Gestión y Métodos Cuantitativos. Universidad Loyola Andalucía \\ gmillan@uloyola.es \\ Leonor M. Pérez* \\ Departamento de Organización de Empresas. Universidad de Córdoba \\ Iperez@uco.es
}

\section{RESUMEN}

El turismo en destinos religiosos ha aumentado en los últimos años convirtiéndose en un motor de desarrollo para muchas poblaciones. No obstante, los estudios sobre la demanda aún son escasos. El objetivo de este artículo es dar a conocer el perfil del turista en distintos destinos religiosos de España e identificar sus particularidades. Se realizó un trabajo de campo en tres de las manifestaciones religiosas más importantes: Camino de Santiago, Romería del Rocío y Semana Santa de Sevilla. Un análisis comparativo entre los tres perfiles mostró algunas semejanzas entre ellos.

Palabras clave: Turismo religioso; peregrinación; perfil del turista; impacto económico.

\section{ABSTRACT}

In recent years, tourism has grown in religious destinations and becomes a key driver for the development in many populations. However, demand studies are still scarce. The aim of this paper is to present the tourist profile in different religious destinations of Spain and identify their characteristics. A fieldwork was conducted in three of the most important religious destinations: Way of St. James, El Rocío pilgrimage and Holy Week in Seville. A comparative analysis between the three profiles showed some similarities between them.

Key words: religious tourism, pilgrimage, tourist profile, economic impact.

Fecha de recepción: noviembre 2015.

Fecha de aceptación: noviembre 2016.

* Autora para la correspondencia 


\section{INTRODUCCIÓN}

El turismo por motivos religiosos es probablemente tan antiguo como la propia religión y, por consiguiente, el tipo de turismo más antiguo que existe (Rinschede, 1992). Sin embargo, actualmente, el turismo religioso ha emergido en muchas regiones como uno de los productos de turismo más importantes. El número de visitantes en destinos religiosos está experimentando un resurgimiento en todo el mundo (Digance, 2003; Organización Mundial del Turismo, 2008), en lugares asociados a casi todas las religiones (Reader, 2007). La Organización Mundial del Turismo (2008) estima que anualmente entre 300 y 330 millones de personas se desplazan por motivos religiosos, generando un impacto económico de unos 13.000 millones de euros (World Religious Travel Association, 2010). A estos datos habría que incluir los de la India y los de otros países asiáticos, de forma que el total de turistas llegaría a más de 500 millones. Una cifra que además ha crecido en los últimos años.

Sin embargo, y aunque hay un número creciente de estudios relacionados con el turismo religioso, las investigaciones sobre esta materia siguen siendo escasas (Cánoves y Blanco, 2011; Millán et al., 2012; Organización Mundial del Turismo, 2008). Y respecto a la demanda, la falta de estadísticas e información cualitativa y cuantitativa sigue siendo un reto (Lanquar, 2008; Triantafillidou et al., 2010).

El objetivo de este artículo es dar a conocer el perfil del turista en los destinos religiosos de España, identificando características comunes en ellos. El potencial del turismo religioso en España hace necesario estudiar la demanda. El turismo religioso puede ser una oportunidad para el desarrollo de muchas áreas, tanto rurales como urbanas. Y los resultados de esta investigación pueden contribuir a que las distintas entidades puedan diseñar planes de marketing más eficaces.

Para llevar a cabo este estudio se utilizaron datos de un trabajo de campo realizado en 2008 en tres de las manifestaciones religiosas más importantes de este país: el Camino de Santiago (300 encuestas), la Romería de la Virgen del Rocío (1.200) y la Semana Santa de Sevilla (725). Los resultados mostraron varias características semejantes entre los tres perfiles.

A continuación, en primer lugar, se presenta brevemente el concepto de peregrino y turista religioso. En segundo lugar, se muestra la relevancia de este tipo de turismo como motor de desarrollo y su potencial a nivel nacional. Posteriormente, se presenta la metodología de la investigación y los resultados. Y, por último, las conclusiones más relevantes del estudio.

\section{EL CONCEPTO DE PEREGRINO Y TURISTA RELIGIOSO}

La relación entre turismo y religión puede considerarse desde dos perspectivas:

- El turismo religioso, como turismo motivado parcial o exclusivamente por razones religiosas (Rinschede, 1992). Una de las formas más antiguas de turismo.

- El turismo como religión o como viaje espiritual contemporáneo (Sharpley, 2009). El turismo puede verse desde un punto de vista estructural y funcional como el equivalente moderno del peregrinaje tradicional, siendo la experiencia de liminalidad y communitas comunes a ambos fenómenos; o de forma más general, como una experiencia espiritual moderna que contrasta con la condición anómica de las sociedades (post)modernas. 
Este estudio considera el turismo religioso como aquel motivado parcial o exclusivamente por razones religiosas. En esta perspectiva, una de las cuestiones más debatidas entre los autores es la distinción entre turistas y peregrinos. En general, al peregrino se le ha identificado normalmente como un viajero religioso y al turista como alguien que está de vacaciones. Se trata de una polaridad construida culturalmente (Smith, 1992). Pero durante la década de 1970 comenzaron a destacarse similitudes entre ambos (Graburn, 1977; MacCannel, 1973). Desde entonces se ha tratado la complicada relación entre peregrinación y turismo desde diversas perspectivas (económica, política, social, psicológica y emocional) y se han propuesto distintas tipologías de turistas y peregrinos (Smith, 1992; 1989; Cohen, 1992; 1979; MacCannel, 1973).

En general, un grupo de autores, como por ejemplo Cohen (1992), afirma que peregrinos y turistas son muy diferentes entre sí, mientras que otro grupo, como Eade (1992), sostiene que es imposible, y no tiene sentido, distinguir entre ambos, porque cuando viajan utilizan los mismos recursos y servicios. Sólo se diferencian por tanto en términos de sus adherencias y preferencias devocionales.

En este sentido, autores como Smith (1992) han sostenido una perspectiva que considera a los dos grupos dentro de una graduación continua que va desde la peregrinación piadosa basada en la fe hasta el turismo estrictamente secular. En una posición intermedia estaría el turismo religioso propiamente dicho, donde puede distinguirse entre un viajero más peregrino que turista, un viajero tan peregrino como turista o un viajero más turista que peregrino, según predomine la fe o lo profano en sus motivaciones y actividades. Este amplio espectro refleja las múltiples y cambiantes motivaciones de los viajeros, cuyos intereses y actividades podrían cambiar (consciente o inconscientemente) desde la peregrinación al turismo y viceversa.

Varios estudios han revelado que la mayoría de los visitantes en destinos religiosos viven experiencias que se sitúan en el punto medio del modelo de Smith, sin que se trate por tanto de experiencias religiosas devotas ni de experiencias puramente seculares (Collins-Kreiner y Gatrell, 2006). No obstante, hay que considerar también que no todos los destinos sagrados atraen por igual a ambos, turistas y peregrinos (Olsen y Timothy, 2006). Según Nolan y Nolan (1992), diferentes categorías de destinos religiosos atraen a diferentes clases de visitantes, cada uno en busca de experiencias distintas. Estos autores, cuando describen el sistema de turismo religioso en Europa, distinguen entre santuarios de peregrinación con una fuerte atracción de devotos religiosos pero pocas características para atraer a turistas seculares; espacios religiosos con carácter histórico-artístico significativo, que funcionan como centros de atracción de devotos y como atracciones de turismo religioso debido a sus características históricas, artísticas y/o escénicas; y lugares donde los encuentros o celebraciones religiosas son la principal atracción.

El continuo enfoque en las diferencias entre peregrinos y turistas ha provocado que muchas investigaciones pasen por alto otras dimensiones y factores que pueden influir en las experiencias del visitante (Collins-Kreiner, 2010), como pueden ser las características socio-demográficas (Bideci y Albayrak, 2016; Sharpley y Sundaram, 2005).

Rinschede (1992) explica que en el contexto del turismo religioso las creencias afectan al comportamiento en el viaje. Aquellos que viajan movidos por la religión tienden a viajar con familiares o grupos organizados, su viaje es altamente estacional, y en algunos destinos existen diferencias socio-demográficas. Por ejemplo, la mayoría de los peregrinos a Lourdes, Francia, son mujeres, a causa de que el género femenino tiene un sentimiento especial hacia los santuarios marianos, mientras que la mayoría de los peregrinos en La 
Meca son hombres como resultado de la posición social de la mujer en el mundo y religión islámicos. De igual forma, algunos destinos son muy populares entre los peregrinos más jóvenes, como las convenciones católicas (McIntosh y Zahra, 2013), mientras que otros lo son entre las personas más mayores, tales como los viajes de peregrinación en el sur de Asia (Nyaupane y Budruk, 2009).

A pesar de todos los esfuerzos para distinguir peregrinación y turismo, cabe aclarar que hoy los límites entre ambos conceptos son muy difusos porque ambos términos han ido evolucionando. En primer lugar, porque el contexto también ha cambiado y no tiene nada que ver con el contexto de peregrinación de por ejemplo la Edad Media (Olsen, 2010). En segundo lugar, el término peregrinación, especialmente desde la década de 1990, cada vez más se utiliza en contextos más amplios y seculares (Margry, 2008), para referir por ejemplo visitas a tumbas de guerra, tumbas o residencias de celebridades y sitios funerarios, que evidencian características tradicionalmente asociadas con las peregrinaciones. La zona cero de Nueva York o Graceland, la mansión de Elvis Presley, son algunos ejemplos. Y en tercer lugar, porque el término turismo, a su vez, cada vez más es observado desde esa segunda perspectiva que considera al turismo como un viaje espiritual (Willson et al., 2013).

\section{EL TURISMO RELIGIOSO COMO MOTOR DE DESARROLLO}

El turismo religioso genera beneficios en los destinos, tanto a niveles individuales como colectivos. Para las autoridades eclesiásticas los beneficios son los siguientes:

- Por una parte, los destinos pueden obtener un mayor volumen de donativos y limosnas. El santuario de Lourdes recibe entre ofrendas, donativos y herencias más de 18 millones de euros al año (el 90\% de sus recursos financieros) (Sanctuaires Notre-Dame de Lourdes, 2012).

- Por otra parte, el desarrollo del turismo en destinos religiosos se puede concebir como una forma de reafirmar la autoridad de la propia institución religiosa en épocas de debilidad (Covell, 2005; Dahlberg, 1991). No obstante, Reader (2007) afirma que el crecimiento de la peregrinación contemporánea, más que implicar alguna forma de renacimiento religioso, puede considerarse una evidencia del creciente rechazo de la religión como una entidad organizada.

- Otros ven en el turismo la oportunidad de acercar a la gente a los templos y así atraer a nuevos fieles. Hay por ejemplo muchos testimonios de personas que comenzaron el Camino de Santiago en un contexto secular y que sin embargo terminaron el camino con fuertes sentimientos religiosos, dadas las experiencias vividas durante el viaje y el contacto con otros cristianos.

- Y otros simplemente muestran su satisfacción por la aportación del turismo y la religión a la sociedad. En este sentido, en una entrevista que los autores tuvieron en 2010 con un arzobispo español, éste manifestaba su alegría respecto a las aportaciones de la Iglesia a la sociedad. No sólo forma buenos cristianos que siempre serán buenos ciudadanos, sino que también puede ayudar en el campo material dado el impacto que el turismo religioso puede generar en el empleo y en la economía, si bien advertía que este último no debe convertirse en un fin en sí mismo. 
Como comenta este arzobispo, el turismo en destinos religiosos no sólo genera beneficios para las autoridades eclesiásticas. Al igual que otras formas de turismo, por supuesto, proporciona beneficios a los servicios de hospitalidad a causa del incremento del número de turistas. No obstante, aporta además otros beneficios más particulares, como serían los siguientes:

- El turista movido por la fe suele mostrarse más satisfecho con la experiencia vivida durante el viaje (Fleischer, 2000) y, en consonancia, suele ser más fiel al destino religioso que el turista tradicional o con otras motivaciones, siendo recurrente al sitio en un periodo de tiempo menor (Robles, 2001; Shuo et al., 2009).

- El turismo religioso posibilita la reactivación de actividades artesanales (Robles, 2001). Por una parte, el turista con motivaciones religiosas siempre ha tenido una verdadera obsesión por llevarse reliquias representativas del destino. Desde polvo del camino hasta musgo de las puertas de las iglesias o cera de las velas de los altares. De hecho, algunos autores, como Swanson y Timothy (2012), consideran que los verdaderos orígenes de los souvenirs modernos son los souvenirs de carácter religioso que se adquirían durante las peregrinaciones. Hoy día, son muchos los turistas religiosos que igualmente sienten el deseo de llevarse algún recuerdo o dejar algún ex-voto (ver por ejemplo, Clarke y Raffay, 2015). Así, la elaboración de artículos con un toque artesanal y con motivos típicos del lugar es sin duda una alternativa para gremios artesanales tradicionales, así como nuevas expresiones de arte popular (Robles, 2001). Según Bar y Cohen-Hattabm (2003), además, el gasto de los peregrinos en compras es más alto que el del resto de viajeros. No obstante, hay que tener en cuenta que el poder adquisitivo de los peregrinos varía según el contexto. En Israel, por ejemplo, los peregrinos son de menor estatus económico que los otros turistas (Fleischer, 2000; Collins-Kreiner y Kliot, 2000). Aun así, los peregrinos muestran en las compras un mayor interés que los turistas más seculares, puesto que consideran que no es una actividad que perturbe la atmósfera religiosa (Collins-Kreiner y Kliot, 2000). A medida que el turista es más secular se interesa más en actividades de otro tipo (culturales y de ocio). Y según Irimias et al. (2016) son los viajeros más fieles los que donan más y están más dispuestos a comprar recuerdos de carácter sagrado.

Por otra parte, el desarrollo y mantenimiento de las distintas actividades religiosas (preparación de romerías, mantenimiento de imágenes, etc.) favorece a distintos oficios y actividades artesanales (bordados, orfebrería, imaginería, tallado, dorado,...), generando un apreciable movimiento económico a lo largo del año (Cámara de Comercio de Sevilla, 2010).

- Una adecuada gestión del crecimiento turístico de carácter religioso puede incidir en la conservación, puesta en valor y mejora del patrimonio cultural de los destinos turísticos (Organización Mundial del Turismo, 2008). España, por ejemplo, ha recuperado parte de su patrimonio cultural e histórico gracias al desarrollo de productos turísticos como la Red de Juderías, o el Camino de Santiago.

- El turismo religioso quizás sea uno de los pocos tipos de turismo que puede fortalecerse en épocas de crisis como la actual (Millán et al., 2010). A pesar de que las personas no participen de forma regular en prácticas religiosas, todavía reconocen la importancia de la religión en los momentos cruciales de sus vidas (Davie, 2007). Así, lugares como Guadalupe (México) o Santiago de Compostela (España) han batido récord de turis- 
tas en plena crisis económica. Según un estudio elaborado por la organización Gallup (2009), en las poblaciones con mayores problemas económicos la religión es en realidad una fuerza poderosa y positiva, "una forma literal de seguro social" en tiempos de crisis. En la actual crisis económica, con la angustia que se ha extendido sobre millones de personas, han sido muchos los que han regresado a los templos. Como Bloch escribió, "cuando hay esperanza, hay religión" (citado por Vukonic, 1992).

- Por último, Lanquar (2008) subraya que las peregrinaciones y los encuentros religiosos permiten trabar más fácilmente relaciones de paz entre los pueblos y promueven un "turismo solidario" que contribuye a la lucha contra la pobreza y al desarrollo sostenible de la humanidad.

No obstante, no todo son beneficios. El turismo religioso también implica costes significativos: impactos medioambientales; conflictos sociales entre los turistas más seculares y los peregrinos más devotos; y costes económicos, tanto para las entidades que individualmente se embarcan en el desarrollo de este tipo de turismo, como para el desarrollo de infraestructuras de apoyo y de acciones de marketing apropiadas. En consecuencia, el desarrollo del turismo religioso depende en general de políticas y programas de organismos gubernamentales, del marketing de organizaciones de turismo o del destino, de acciones independientes por parte de empresarios y de acciones independientes por parte de las instituciones religiosas.

En algunos lugares, como por ejemplo en Lourdes (Francia), el desarrollo del turismo religioso se ha ido generando a raíz de las decisiones e iniciativas de autoridades religiosas locales y regionales (Harris, 1999). La planificación estratégica por parte de los directivos de lugares y eventos sagrados es clave para el desarrollo sostenible del turismo religioso de una zona (Ambrosio y Pereira, 2007).

Hay que precisar que la planificación estratégica se ha ido incorporando de forma progresiva en los diferentes enfoques de planificación turística (Getz, 1986; Hall, 2000), fomentando un análisis global del entorno competitivo, así como la coordinación y cooperación entre stakeholders (Vila et al., 2010). Y, afortunadamente, ha resultado fácil de integrar en los procesos de dirección (Ansoff, 1988; Hall, 2000; Ivars, 2004; Porter, 1982). Sin embargo, aunque en general la planificación turística ha evolucionado notablemente, en el segmento del turismo religioso esta evolución ha sido mucho más lenta y complicada. Shackley (2001a, 2008) afirma que tan sólo una minoría de directivos de lugares y eventos religiosos lleva a cabo alguna forma de planificación estratégica, algunas veces debido en parte a la naturaleza de sus premisas y dirección, en parte por razones religiosas, en parte por falta de recursos en términos financieros y de experiencia. No obstante, la planificación estratégica es clave, sobre todo si se tiene en cuenta la complejidad añadida en la dirección de estos lugares y eventos donde coinciden religión y turismo (Shackley, 2001a; Olsen, 2006). Una complejidad añadida que se manifiesta tanto en cuestiones de gestión interna como en cuestiones de gestión externa (Millán et al., 2012).

Entre los desafíos de gestión externa destacan las presiones a las que hacen frente los directivos al negociar con los distintos stakeholders del sector turístico que tienen algún interés en el lugar (Olsen, 2006): desde gobiernos, organizaciones, planificadores urbanos, directivos de turismo regional y local, agencias de desarrollo económico regional,... Y además tratar con otros factores externos relacionados con su macroentorno, sobre todo los de carácter político y social (Shackley, 2001b). 
Como desafíos internos, destaca la dificultad de dirigir el volumen creciente de visitantes mientras se mantiene en equilibrio la necesidad de preservar el lugar, tanto el entorno físico como el medioambiental, con la provisión de una alta calidad de experiencia para los visitantes. Conforme aumenta el número de visitantes resulta más difícil mantener una atmósfera conducente al culto y la contemplación y, al mismo tiempo, es muy probable que aumente la diversidad en las motivaciones y expectativas de los visitantes (Santos, 2003). Sin duda, es necesario entender a los visitantes: conocer su perfil y comprender qué satisface aquello que vayan buscando (de Sousa, 1993). Es fundamental para sentar las bases de la planificación turística.

\section{TRADICIÓN RELIGIOSA Y TURISMO EN ESPAÑA}

En España, según el Centro de Investigaciones Sociológicas (CIS, 2013), la mayor parte de la población (un 72,1\%) se declara católica. El 24,6\% de la población no se reconoce en ninguna religión (definiéndose como ateos o no creyentes). Existen también minorías islámicas, protestantes y ortodoxas, así como otros grupos, como judíos, budistas, baha'is o mormones, entre otros. Esta población creyente podría considerarse el potencial del mercado nacional del turismo religioso.

No obstante, la población española es actualmente poco practicante en su conjunto. Según una encuesta realizada por el CIS en el año 2013, el 64,7\% de los autodefinidos como creyentes de alguna religión dice no ir a misa o a otros oficios religiosos nunca o casi nunca y el $20,2 \%$ dice ir alguna vez al mes o varias veces al año, mientras el 12,1\% dice acudir a oficios religiosos casi todos los domingos y días festivos, y un 1,8\% que va varias veces por semana ${ }^{1}$.

En turismo religioso, España es un importante emisor y receptor. Este país cuenta con numerosos centros de peregrinación y eventos de carácter religioso a lo largo de todo el territorio, que generan un gran interés. La mayoría de ellos, lejos de desaparecer, están experimentando un crecimiento importante en el número de turistas. En la actualidad, tres de las cinco principales ciudades Santas del mundo son españolas. Junto a Jerusalén y Roma se encuentran Santiago de Compostela, Caravaca de la Cruz y Santo Toribio de Liébana.

En España los destinos de peregrinación acogen alrededor de 17 millones de visitantes al año (Arregui, 2009), encabezados por el más famoso centro de turismo religioso del país, la Catedral de Santiago de Compostela (figura 1). Estos destinos se encuentran fuertemente ligados a la cultura y a la historia cristiana del país, y atraen tanto a peregrinos como a visitantes interesados por el símbolo de identidad que representan, su valor cultural o la experiencia

1 En general, muchas sociedades modernas se han ido caracterizando en las últimas décadas por un incremento de la secularización, o dicho de otra forma, por una disminución en la percepción de la importancia de las instituciones y prácticas religiosas. Tal declive se evidencia en la menor participación en la religión organizada o, en concreto, en una menor asistencia a servicios religiosos (Stark et al., 2005). No obstante, es importante destacar que este deterioro no se ha traducido en un vacío religioso. La religión, en el sentido tradicional de la palabra, no está en decadencia, sino que más bien está tomando una forma diferente. Las sociedades modernas siguen siendo religiosas, pero la religión es cada vez más des-institucionalizada (Harvey, 2003). Instituciones religiosas, teologías prescritas y rituales están siendo reemplazados por la espiritualidad. Contrastando con la rigidez organizada de prácticas religiosas tradicionales, la espiritualidad se presenta en muchas ocasiones como una manifestación post-moderna de la religión, que refleja una búsqueda individual de sentido y armonía, al igual que una conexión con el mundo (Pargament, 1999). Así, ha resurgido en los últimos años una etapa post-secular donde la religiosidad es individual y personal, sirviendo como fuente de valores y normas (Nilsson y Tesfahuney, 2016). 
espiritual que pueden aportar. Muchos de estos destinos han sido objeto de estudio por diversos autores (Andrés y Espejo, 2006; Gil de Arriba, 2006; Porcal, 2006; Santos, 2006; Villa, 2006).

Figura 1

PRINCIPALES DESTINOS DE PEREGRINACIÓN EN ESPAÑA CON PROYECCIÓN INTERNACIONAL

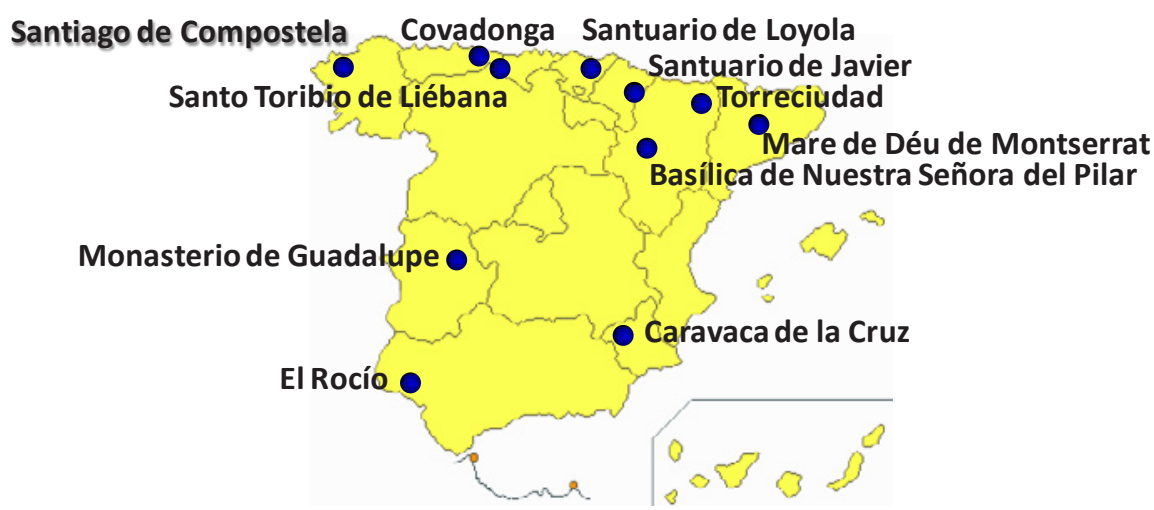

Fuente: elaboración propia a partir de Arregui, 2009.

Nota: A continuación se especifica el volumen de visitantes:

\begin{tabular}{|c|c|c|}
\hline Nombre & $\begin{array}{l}\text { Media de visitantes al año } \\
\text { (incluido peregrinos) }\end{array}$ & Peregrinos \\
\hline Catedral de Santiago de Compostela, Galicia & Más de un millón & $\begin{array}{l}262.516(2015)(a \\
\text { pie, bici o caballo) }\end{array}$ \\
\hline Nuestra Señora del Rocío, en Andalucía & $\begin{array}{l}5.000 \\
\text { Más de un millón los días de romería }\end{array}$ & n.c. \\
\hline Mare de Déu de Montserrat, en Cataluña & Más de un millón & n.c. \\
\hline Basílica Nuestra Señora del Pilar, en Zaragoza & Más de un millón & n.c. \\
\hline Nuestra Señora de Covadonga, en Asturias & Env. $800.000-900.000$ & $\begin{array}{l}200.700 \text { (en grupo) } \\
\text { (2006) }\end{array}$ \\
\hline Santo Toribio de Liébana, en Cantabria & $\begin{array}{c}1.079 .301 \\
\text { (Año Jubilar 2006-2007) }\end{array}$ & n.c. \\
\hline Monasterio de Guadalupe, en Extremadura & 405.000 & 225.000 \\
\hline Torreciudad, en Aragón & $300.000-400.000$ & $225.000-300.000$ \\
\hline Santuario de Javier, en Navarra & $\begin{array}{c}150.000-180.000 \\
(400.000 \text { en } 2006 \text { V Centenario) }\end{array}$ & n.c. \\
\hline Caravaca de la Cruz, en Murcia & Env. $100.000-150.000$ & $\begin{array}{l}741.700 \text { en el Año } \\
\text { Santo } 2003\end{array}$ \\
\hline Santuario de Loyola, en País Vasco & $\begin{array}{c}\text { Santa Casa (casa natal de Íñigo de } \\
\text { Loyola): } 100.000 . \text { Más del doble en la } \\
\text { basílica. }\end{array}$ & 15.000 \\
\hline
\end{tabular}

El Camino de Santiago, la Semana Santa y las romerías son quizás las tres manifestaciones religiosas más significativas de España. Así, a continuación se hace una breve introducción a ellas. 


\section{IV.1. El Camino de Santiago}

Santiago de Compostela, el lugar donde se encuentra la tumba del Santo y Apóstol Santiago, es sin duda uno de los mayores centros de peregrinación cristiana desde el Medievo, junto con Roma y Jerusalén. A lo largo de su historia, el Camino de Santiago $^{2}$ ha pasado por avatares muy diversos, sucediéndose periodos de apogeo y de oscuridad. Tras las Edades Media y Moderna, el camino fue perdiendo importancia, pero a partir de la década de 1970 comenzó a resurgir (figura 2), especialmente a partir de 1990 (figura 3). Esta tendencia creciente fue posible gracias al apoyo de las administraciones, las visitas del Papa a Santiago (en 1982 coincidiendo con año jubilar ${ }^{3}$ y en 1989 con motivo de la IV Jornada Mundial de la Juventud), el renovado esfuerzo de la Iglesia y el desarrollo de múltiples asociaciones y cofradías.

Figura 2

NÚMERO DE PEREGRINOS EN EL CAMINO DE SANTIAGO (1970-1990)

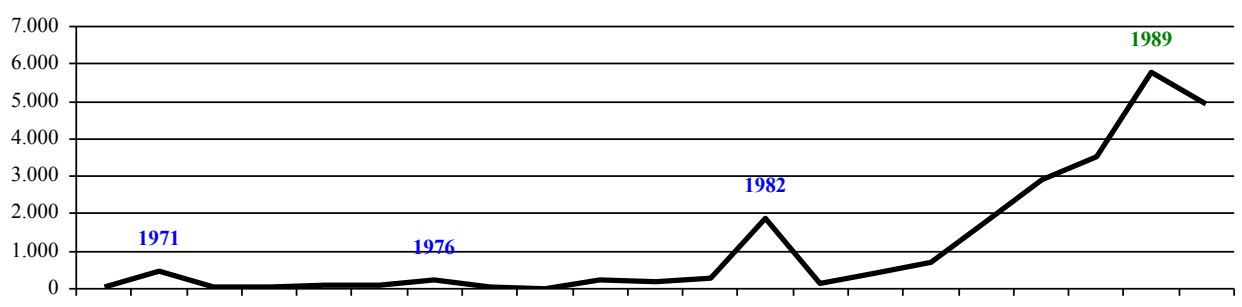

$\begin{array}{lllllllllllllllllllll}1970 & 1971 & 1972 & 1973 & 1974 & 1975 & 1976 & 1977 & 1978 & 1979 & 1980 & 1981 & 1982 & 1983 & 1984 & 1985 & 1986 & 1987 & 1988 & 1989 & 1990\end{array}$

año jubilar - IV dia mundial de la juventud

Fuente: elaboración propia a partir de las estadísticas de la Oficina de Acogida del Peregrino (2015)

Figura 3

NÚMERO DE PEREGRINOS EN EL CAMINO DE SANTIAGO (1990-2012)

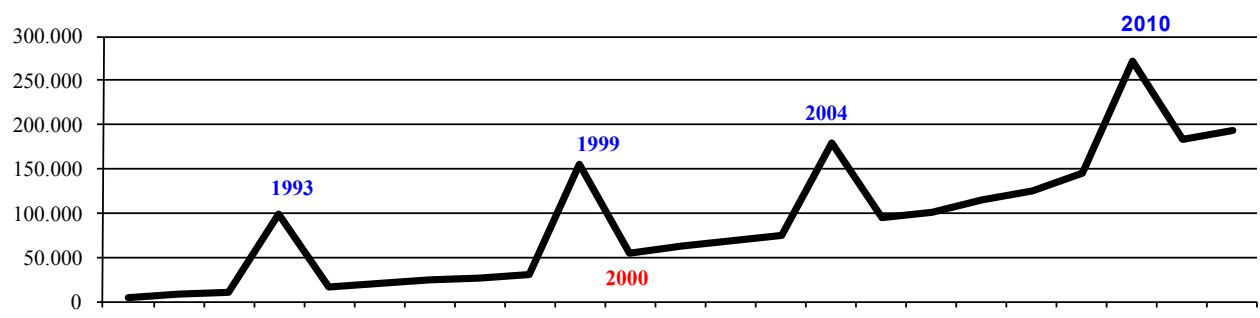

19901991199219931994199519961997199819992000200120022003200420052006200720082009201020112012

Año Jubilar - Capital Europea de la Cultura

Fuente: elaboración propia a partir de las estadísticas de la Oficina de Acogida del Peregrino (2015).

2 El Camino de Santiago consta de varias rutas (el camino francés, siendo esta la más transitada, el inglés, la vía de la plata, el camino mozárabe, el camino primitivo, etc...)

3 Año en que el día de Santiago, 25 de julio, coincide en domingo. 
En 1987 el Camino de Santiago fue declarado Itinerario Cultural Europeo debido a su importancia como vínculo histórico y cultural de la historia de la cristiandad, así como a su innegable valor universal, ya que es un camino que es y ha sido recorrido por miles de peregrinos de toda Europa. Más tarde, en 1993 el Camino fue declarado por la UNESCO Patrimonio Mundial de la Humanidad.

En ese mismo año, en 1993, fue cuando el Camino comenzó un verdadero resurgir gracias a su desarrollo como producto turístico. El gobierno autónomo gallego (la Xunta de Galicia) apostó por potenciar el valor del Camino de Santiago como un recurso turístico. De este modo se lanzó una gran campaña de marketing para el Jacobeo de 1993: Xacobeo 93. Gracias a este plan se restauraron tramos de la ruta y las infraestructuras para peregrinos. Además, se logró la colaboración de todas las comunidades autónomas por las que atraviesa el Camino en sus diversas vertientes (camino francés, del norte, inglés, portugués, etc.). El éxito fue sin duda espectacular. No obstante, se produjo una excesiva turistificación que llevó a una pérdida de los valores tradicionales (Tilson, 2005). Así, a partir del Xacobeo 99 se trató de equilibrar mejor los aspectos comerciales y espirituales. Nilsson y Tesfahuney (2016) apuntan a una aparente paradoja. Por un lado, el aumento de la turistificación del Camino implica una erosión de sus significados y simbolismos religiosos. Pero, sin embargo, la creciente turistificación a su vez testifica un resurgimiento de la religión y una expansión de los lugares y espacios post-seculares.

Según Lois y Santos (2015), el éxito de esta ruta se basa en el hecho de que el nuevo turista mezcla motivaciones de peregrinación (desplazamiento por motivos religiosos o espirituales) con motivaciones turísticas, tales como la búsqueda de paisajes diferentes y la necesidad de relax y de escape de las presiones del día a día. A través de esta peregrinación las personas pueden participar en prácticas espirituales que les ayudan a tratar con el mundo moderno y encontrar un sentido a sus vidas incluso a pesar de rechazar la religión como una entidad organizada (Reader, 2007). Así, en Santiago de Compostela se mezclan de múltiples formas la religión tradicional (institucional, organizada) y lo post-secular (formas personales o individualizadas de creencias religiosas) (Nilsson y Tesfahuney, 2016).

El Observatorio Turístico de Santiago de Compostela y la Oficina de Acogida del Peregrino elaboran respectivamente estadísticas sobre el perfil del turista en Santiago de Compostela y en el Camino.

\section{IV.2. La Semana Santa}

La Semana Santa es sin duda una de las manifestaciones religiosas más populares de España. Se celebra durante la última semana de la Cuaresma, desde el Domingo de Ramos hasta el Domingo de Resurrección, en los meses de marzo o abril. En España se distingue entre Procesiones, Representaciones de la Pasión, Encuentros de Imágenes y Automortificaciones.

Las Procesiones son las más extendidas por todo el territorio nacional y representan los momentos de pasión, muerte y resurrección de Cristo con imágenes de gran valor artístico y monumental. Las representaciones de la Pasión son actos religiosos principalmente localizados en Cataluña y Valencia. Los Encuentros de Imágenes representan normalmente el encuentro del Hijo de Dios y la Virgen. Las automortificaciones intentan emular el sufrimiento de Cristo, por ejemplo arrastrando cruces o cadenas por un recorrido como acto de penitencia y están ampliamente desarrolladas sobre todo en el norte de España (Cánoves, 2006). 
Actualmente, veintiuno de estos eventos celebrados en conmemoración de la Semana Santa están declarados como Fiestas de Interés Turístico Internacional (ver Tabla 1), por ser acontecimientos que suponen la manifestación de valores culturales y de tradición popular, con especial consideración en sus características etnológicas y con una especial importancia como atractivo turístico.

Tabla 1

FIESTAS DE INTERÉS TURÍSTICO INTERNACIONAL

CELEBRADAS EN CONMEMORACIÓN DE LA SEMANA SANTA

\begin{tabular}{|c|l|c|}
\hline Comunidad Autónoma & \multicolumn{1}{|c|}{ Evento } & Año de concesión \\
\hline \multirow{5}{*}{ Andalucía } & Semana Santa en Málaga & 1980 \\
\cline { 2 - 3 } & Semana Santa en Sevilla & 1980 \\
\cline { 2 - 3 } Castilla La Mancha & Semana Santa en Granada & 2009 \\
\hline \multirow{5}{*}{ Castilla y León } & Semana Santa en Cuenca & 1980 \\
\cline { 2 - 3 } & Semana Santa en Hellín (Albacete) & 2007 \\
\cline { 2 - 3 } & Semana Santa en Toledo & 2014 \\
\hline & Semana Santa en Valladolid & 1980 \\
\cline { 2 - 3 } & Semana Santa en Zamora & 1985 \\
\cline { 2 - 3 } & Semana Santa en León & 2002 \\
\cline { 2 - 3 } & Semana Santa en Salamanca & 2003 \\
\cline { 2 - 3 } & Semana Santa en Medina de Rioseco (Valladolid) & 2009 \\
\cline { 2 - 3 } & Semana Santa en Medina del Campo (Valladolid) & 2011 \\
\cline { 2 - 3 } & Semana Santa en Palencia (Palencia) & 2012 \\
\hline \multirow{5}{*}{ Comunidad Valenciana } & Procesión del Domingo de Ramos de Elche (Alicante) & 1997 \\
\cline { 2 - 3 } & Semana Santa en Orihuela (Alicante) & 2010 \\
\cline { 2 - 3 } & Semana Santa en Crevillente (Alicante) & 2011 \\
\hline Extremadura & Semana Santa en Cáceres & 2011 \\
\hline Galicia & Semana Santa en Vivero (Lugo) & 2013 \\
\hline \multirow{5}{*}{ Murcia } & Semana Santa en Cartagena (Murcia) & 2005 \\
\cline { 2 - 3 } & Semana Santa en Lorca (Murcia) & 2007 \\
\cline { 2 - 3 } & Semana Santa en Murcia & \\
\hline & & \\
\hline
\end{tabular}

Fuente: Rutas por España (2015).

De igual forma, más de treinta eventos que conmemoran la Semana Santa han sido declarados Fiesta de Interés Turístico Nacional (Revista Ibérica, 2015). Esta es una denominación honorífica otorgada a festejos o acontecimientos que se celebran en España y que ofrecen interés real desde el punto de vista turístico.

En los municipios en los que se celebra, y en sus entornos más próximos, la preparación y celebración de la Semana Santa genera un gran impacto socio-económico debido a que moviliza a un gran número de actores. Desde aquellos cuya producción se destina a la preparación de la Semana Santa (cofradías, bordadores, orfebres, doradores, imagineros, floristas, cereros y diversas industrias que trabajan para las cofradías) hasta aquellos relacionados con las ramas de comercio al por menor, servicios hoteleros y de alojamiento, cafeterías, bares, 
restaurantes o agencias de viajes, entre otros; y por supuesto el público asistente. Los municipios se convierten en un gran escenario donde el espacio público se transforma en espacio ritual/festivo (Jiménez, 2008).

No obstante, hay que tener en cuenta que la Semana Santa afecta a la sociedad de manera global y permanente abarcando casi todo el año. Por una parte, destaca la actividad cotidiana que mantienen los miembros de las hermandades. Los hermanos suelen reunirse con cierta frecuencia en sus sedes sociales. Y por otra parte, los oficios y actividades artesanales (bordados, orfebrería, imaginería, tallado, dorado,...) que se mantienen en pleno auge y generan un apreciable movimiento económico a lo largo del año gracias a la necesidad de las distintas actividades cofradieras. En España existen más de dos mil cofradías y hermandades, con un número de cofrades y hermanos en torno a los dos millones.

La ciudad de Sevilla, con 696.676 habitantes (año 2014) y 68 Cofradías de Penitencia, cuenta con una de las procesiones más antiguas, populares y con más tradición de España. En esta ciudad, el número de turistas durante este evento religioso ha experimentado un gran incremento, cifrándose en un 34,5\% desde el año 1999 al año 2009 (pasando de recibir 676.000 a 909.000 turistas) (Cámara de Comercio de Sevilla, 2010).

El impacto económico de la Semana Santa en Sevilla en el año 2015 fue de 280 millones de euros (un 16,5\% más que en el año 2009), lo que supone el 1,26\% del PIB de la ciudad y el $0,8 \%$ del PIB total de la provincia. No existen estudios que analicen el impacto económico de la Semana Santa a nivel nacional, aunque a nivel local existen algunos estudios como el de la Cámara de Comercio de Sevilla (2010). Según esta investigación, en Sevilla en el año 2009 el efecto directo (el gasto en que incurrieron las instituciones públicas y privadas para la celebración del evento) fue de unos 8,5 millones de euros, de los que cinco fueron involucrados por el Ayuntamiento y tres por entidades como el Consejo General de Hermandades y Cofradías. El efecto indirecto (el gasto realizado por los participantes) fue de 68 millones de euros, siendo 46,3 millones correspondientes a los asistentes locales y 21,7 millones a los asistentes foráneos. El efecto inducido ascendió a 163,7 millones. Estas cifras subrayan la notable significación que tiene la Semana Santa sobre la actividad del sector turístico y de ocio para la ciudad y su entorno más cercano.

\section{IV.3. Las romerías}

Las romerías se celebran en cada pueblo en honor a la Virgen o Santo que es patrón de la zona. Aquí el ambiente es festivo, alegre y lleno de colorido. Entre todas, destaca la Romería del Rocío, que está declarada Fiesta de Interés Turístico Internacional desde 1980, y que además recibió en 1993 la visita del Papa Juan Pablo II.

Esta romería se celebra en la aldea de El Rocío, situada en el municipio de Almonte, en Huelva (Andalucía). Almonte es un municipio rural con apenas 22.000 habitantes. Sin embargo, durante la celebración de la romería, más de un millón de personas y más de un centenar de hermandades diferentes llegan de todas partes de España, e incluso del extranjero. A principios de la década de 1970 el número de peregrinos apenas superaba los 150.000 .

La peregrinación al Rocío se remonta a 1653, cuando la Virgen de Las Rocinas fue nombrada santa patrona de Almonte. Originalmente esto tuvo lugar el 8 de septiembre. Pero 
desde 1758 la Virgen ha sido conocida como la Virgen de El Rocío, y la celebración ha tenido lugar cada año en el segundo día de Pentecostés, en lunes. Por eso su fecha es variable, pudiendo oscilar entre mayo y junio.

Cada año, las diferentes hermandades rocieras parten de sus bases en las distintas provincias con la suficiente antelación para estar el sábado en la aldea del El Rocío y participar en los actos de la romería, que se prolongan hasta el lunes. Más concretamente, en la actualidad acuden a la Romería 110 Hermandades filiales de la Hermandad Matriz de Almonte, además de 34 no filiales, 20 asociaciones privadas, 174 Agrupaciones nacionales y 10 agrupaciones internacionales (Ayuntamiento de Almonte, 2012).

La peregrinación se suele hacer a caballo, en carreta o a pie, y vistiendo ropa flamenca. Durante el día, las hermandades avanzan en el camino con alegría, cantando, mientras que por la noche, acampan al aire libre, alrededor de una hoguera, organizando una fiesta con cante y baile.

Según van llegando a la aldea, los romeros acampan a la espera de que acudan el resto de las hermandades. El sábado desfilan para presentarse con el simpecado (el estandarte de la hermandad) ante la Virgen mientras repican las campanas. El domingo se celebran los oficios religiosos y, por la noche, se espera al momento más emocionante del fin de semana: "el salto de la reja", cuando la gente de Almonte salta la valla para sacar a la Virgen de la ermita y pasearla en hombros por la aldea el lunes por la mañana.

Para los habitantes de la zona, que se dedican principalmente a la agricultura, la romería supone creación de puestos de trabajo, reactivación de la economía local y regional y la mejora de los servicios, siendo por tanto una oportunidad para el desarrollo de actividades turísticas, de inversión e innovación. En concreto, se estima que el impacto económico de la romería en la provincia de Huelva es aproximadamente de 120 millones de euros (Ayuntamiento de Almonte, 2012).

Cabe destacar que la Romería es la fiesta principal dedicada a la Virgen del Rocío, pero no es la única celebración que se lleva a cabo en la zona. También hay otras actividades de gran calado y seguimiento, como son la Navidad y Noche Vieja, las peregrinaciones que cada fin de semana realizan las Hermandades filiales hasta la aldea entre septiembre y hasta la primavera siguiente, La Candelaria, en Semana Santa, la procesión extraordinaria, la ida de la Virgen, la Saca de las Yeguas, La Feria de Almonte y el Rocío Chico. Todas tienen un gran seguimiento, aunque con un carácter más local.

En resumen, dado el potencial del turismo religioso en España, es necesario estudiar la demanda analizando su perfil, pues esta puede suponer un motor de desarrollo para determinadas áreas, tanto de carácter urbano como rural.

\section{METODOLOGÍA DE LA INVESTIGACIÓN Y RESULTADOS}

El objetivo de esta investigación es dar a conocer el perfil del turista de destinos religiosos en España, tomando como referencia tres de las manifestaciones religiosas más relevantes: el Camino de Santiago, la Romería de la Virgen del Rocío y la Semana Santa de Sevilla.

Para ello se llevó a cabo un trabajo de campo en cada uno de los destinos señalados durante el año 2008 (ver tabla 2). 
Tabla 2

FICHA TÉCNICA DE LAS ENCUESTAS

\begin{tabular}{|l|l|l|l|}
\hline & \multicolumn{1}{|c|}{ Camino de Santiago } & \multicolumn{1}{|c|}{ Romería del Rocío } & \multicolumn{1}{c|}{ Semana Santa de Sevilla } \\
\hline Población & $\begin{array}{l}\text { Turistas de ambos sexos } \\
\text { mayores de 18 años que } \\
\text { reciben la Compostela tras } \\
\text { realizar el camino }\end{array}$ & $\begin{array}{l}\text { Turistas de ambos sexos } \\
\text { mayores de 18 años que } \\
\text { realizaron el camino al a } \\
\text { Rocío }\end{array}$ & $\begin{array}{l}\text { Turistas de ambos sexos } \\
\text { mayores de 18 años que } \\
\text { asisten a la Semana Santa } \\
\text { de Sevilla }\end{array}$ \\
\hline Tamaño muestral & 300 encuestas válidas & $\begin{array}{l}1.200 \text { encuestas } \\
\text { válidas }\end{array}$ & 725 encuestas válidas \\
\hline Error muestral & $\pm 2,10 \%$ & $\pm 3,67 \%$ & $\pm 4,23 \%$ \\
\hline Nivel de confianza & $95 \% ; \mathrm{p}=\mathrm{q}=0,5$ & $95 \% ; \mathrm{p}=\mathrm{q}=0,5$ & $95 \% ; \mathrm{p}=\mathrm{q}=0,5$ \\
\hline $\begin{array}{l}\text { Fecha del trabajo de } \\
\text { campo }\end{array}$ & 2008 & 2008 & 2008 \\
\hline
\end{tabular}

Fuente: elaboración propia.

El tamaño de las muestras se determinó en función de la población de turistas de cada destino. Al Rocío acuden más de un millón de turistas al año, a la Semana Santa unos 900.000 y al Camino de Santiago, un año que no sea jubilar, no llegan a los 200.000.

Los cuestionarios se realizaron con entrevistas directas mediante encuestadores. En el caso del Camino de Santiago, las encuestas tuvieron lugar en los albergues del camino, y más concretamente en el Camino Francés, por ser el más transitado (Oficina de Acogida del Peregrino, 2015); durante la Semana Santa se encuestó en diversos puntos de Sevilla; y en el Rocío en algunas casas de hermanad y cerca de la basílica.

Cada cuestionario se componía de cuatro bloques. Un primer bloque referente al perfil sociodemográfico del turista (género, edad, nivel de estudios,...). Un segundo bloque sobre las características del viaje (días empleados, gasto realizado,...). Un tercer bloque sobre la motivación que ha impulsado a realizarlo. Y, por último, sobre las opiniones, valoraciones y satisfacción con el viaje realizado y los lugares visitados.

Según los resultados obtenidos, el perfil de los turistas varía en función de las características del lugar o evento religioso. En la Tabla 3 se resume el perfil en cada uno de ellos.

Los resultados sobre el perfil del turista en el Camino de Santiago, en general, están en consonancia con las estadísticas de la Oficina de Acogida del Peregrino (2015), según las cuales hay un predominio de hombres (53\%), con edades entre 30 y 60 años (55\%), que realizan el viaje por una mezcla de motivaciones religiosas y de otro tipo $(54 \%)$ y que repetirían el viaje (88\%). No obstante, estas estadísticas indican una mayor presencia de turistas internacionales (53\%) y de personas que realizan el viaje en familia (un 43,6\% viaja en familia frente a un $32 \%$ que lo hace solo).

Al comparar los tres tipos de turistas de nuestro estudio se detectan diferencias estadísticamente significativas $(\mathrm{p}<0,05)$ en la mayoría de las variables. En concreto, las diferencias más significativas $(\mathrm{p}<0,01)$ entre los tres perfiles se producen en el estado civil, el nivel de renta, el gasto medio diario, con quién realiza el viaje, su duración, la motivación y la opinión sobre la infraestructura hotelera. Estas diferencias se deben principalmente a las características específicas de cada una de los destinos y eventos analizados. 
Tabla 3

PERFIL DEL TURISTA EN TRES MANIFESTACIONES RELIGIOSAS DIFERENTES: CAMINO DE SANTIAGO, ROMERÍA DEL ROCIOO Y SEMANA SANTA DE SEVILLA

\begin{tabular}{|c|c|c|c|c|}
\hline Variable & Categorías & $\begin{array}{c}\text { Camino de Santiago } \\
(\%)\end{array}$ & $\begin{array}{c}\text { Romería del Rocío } \\
(\%)\end{array}$ & $\begin{array}{c}\text { Semana Santa de } \\
\text { Sevilla } \\
(\%)\end{array}$ \\
\hline \multirow{2}{*}{ Género } & Hombre & 58,3 & 42,4 & 55,2 \\
\hline & Mujer & 41,7 & 57,6 & 44,8 \\
\hline \multirow{5}{*}{ Edad } & 18-35 años & 32,9 & 41,1 & 39,6 \\
\hline & 36-45 años & 52,2 & 44,3 & 42,8 \\
\hline & 46-55 años & 5,7 & 9,4 & 3,4 \\
\hline & 56-65 años & 8,3 & 4,2 & 12,1 \\
\hline & Más de 65 años & 0,9 & 1,00 & 2,1 \\
\hline \multirow{4}{*}{ Nivel de estudios } & Sin estudios & 2,6 & 3,1 & 4,4 \\
\hline & Estudios básicos & 27,8 & 36,9 & 12,7 \\
\hline & Estudios medios & 63,4 & 51,7 & 68,5 \\
\hline & Estudios superiores & 6,2 & 8,3 & 14,4 \\
\hline \multirow{4}{*}{ Estado civil } & Soltero & 67,2 & 27,6 & 35,9 \\
\hline & Casado & 25,4 & 46,8 & 54,8 \\
\hline & Separado & 2,3 & 13,2 & 3,6 \\
\hline & Otros & 5,1 & 12,4 & 5,7 \\
\hline \multirow{5}{*}{ Nivel de renta } & Menos de $600 €$ & 5,3 & 1,2 & 3,2 \\
\hline & $600-1000 €$ & 27,7 & 4,3 & 9,3 \\
\hline & $1001-1500 €$ & 38,9 & 14,8 & 19,3 \\
\hline & $1501-2500 €$ & 25,4 & 13,4 & 35,8 \\
\hline & Más de $2500 €$ & 2,7 & 66,3 & 32,4 \\
\hline \multirow{3}{*}{$\begin{array}{l}\text { Lugar de } \\
\text { procedencia }\end{array}$} & Nacional & 73,2 & 84,6 & 79,5 \\
\hline & UE & 20,1 & 12,3 & 18,4 \\
\hline & Resto de países & 6,7 & 3,1 & 2,1 \\
\hline \multirow{4}{*}{ Duración del viaje } & Menos de 24 horas & 0,01 & 0,3 & 25,6 \\
\hline & Un día & 1,3 & 4,5 & 23,4 \\
\hline & Entre 2 y 3 días & 25,8 & 34,6 & 7,8 \\
\hline & Más de 3 días & 72,89 & 60,6 & 43,2 \\
\hline \multirow{4}{*}{ Gasto medio diario } & Menos de $35 €$ & 75,6 & 0,4 & 10,4 \\
\hline & $36-50 €$ & 14,3 & 3,6 & 27,8 \\
\hline & $51-75 €$ & 7,8 & 28,9 & 15,6 \\
\hline & Mas de $75 €$ & 2,3 & 67,1 & 46,2 \\
\hline \multirow{4}{*}{$\begin{array}{l}\text { Con quién realiza } \\
\text { el viaje }\end{array}$} & Solo & 64,8 & 4,1 & 2,6 \\
\hline & Familiares & 8,6 & 13,6 & 44,8 \\
\hline & Amigos & 14,9 & 73,6 & 51,8 \\
\hline & Otros & 11,7 & 8,7 & 0,8 \\
\hline
\end{tabular}




\begin{tabular}{llccc}
\hline \multirow{2}{*}{ Motivación del viaje } & Solo religiosa & 40,6 & 56,7 & 63,4 \\
& Religiosa y otra & 50,8 & 26,1 & 34,3 \\
& No religiosa & 8,6 & 17,1 & 2,3 \\
\hline \multirow{2}{*}{ Infraestructura } & Satisfecho & 45,2 & 89,6 & 46,7 \\
hotelera & Insatisfecho & 54,8 & 10,4 & 53,3 \\
\hline \multirow{2}{*}{ Repetición del viaje } & Repetiría & 78,3 & 86,2 & 72,5 \\
& No repetiría & 21,7 & 13,8 & 27,5 \\
\hline \multirow{2}{*}{ Satisfacción con el } & Satisfecho & 87,2 & 90,2 & 76,3 \\
viaje & Indiferente & 11,7 & 3,4 & 2,5 \\
& Insatisfecho & 1,1 & 6,4 & 21,2 \\
\hline
\end{tabular}

Fuente: elaboración propia.

En la peregrinación a Santiago de Compostela predomina la presencia de personas solteras $(67,2 \%)$ y la mayoría $(64,8 \%)$ realiza el viaje solo. Por el contrario, en la peregrinación al Rocío y en la celebración de la Semana Santa predominan las personas casadas $(46,8 \%$ y $54,8 \%$ respectivamente) y la mayoría realiza el viaje acompañado de amigos $(73,6 \%$ y $51,8 \%$, respectivamente). Tanto la Romería del Rocío como la Semana Santa son manifestaciones de religiosidad popular que se organizan dentro de hermandades, en las que los hermanos celebran el evento en un ambiente familiar y de amistad. Sin embargo, la peregrinación a Santiago de Compostela ofrece un contexto más propicio para reencontrarse con la fe y vivir experiencias espirituales de forma más individual, autónoma e independiente.

Por otro lado, en términos generales, los peregrinos al Rocío tienen un nivel de renta más elevado (un 66,3\% supera los 2.500 euros/mes), mientras que los peregrinos a Santiago de Compostela poseen un nivel de renta más bajo (un 71,9\% no sobrepasa 1500 euros/mes). Esto se debe a que la romería del Rocío normalmente conlleva realizar unos gastos de más de 800 euros, dada la cantidad de preparativos necesarios para el camino. Estos gastos se centran principalmente en la carriola con los bueyes o el caballo para hacer el camino, sus adornos, el alojamiento en un hotel o una casa de alquiler, la comida o un servicio de catering, el traje de corto y los zahones para los hombres o el traje de flamenca y complementos para las mujeres, los gaiteros y los tamborileros.

Las peregrinaciones a Santiago de Compostela son mucho más sencillas. Los peregrinos no necesitan realizar tantos preparativos y suelen alojarse en albergues. Así, el gasto en el que normalmente se incurre para realizar esta peregrinación es mucho menor, no soliendo superar los 35 euros diarios (un 75,6\% no gasta más de esta cantidad). Esto hace a esta peregrinación más accesible a las clases sociales más bajas, incluso a pesar de que la duración del viaje sea mayor.

En el caso de la Semana Santa de Sevilla, un 68,2\% de los visitantes tiene un nivel de renta superior a 1.500 euros/mes. En este caso, también podría decirse que la visita a Sevilla en esta época es menos accesible a las clases sociales más bajas, principalmente porque los alojamientos suelen elevar sus precios en estas fechas. Así, casi la mitad de los visitantes $(46,2 \%)$ tienen un gasto medio superior a los 75 euros por día. El alto precio del alojamiento propicia que la duración del viaje sea menor (un 25,6\% está en la ciudad menos de 24 horas, y un $23,4 \%$ tan sólo pernocta una noche). 
Respecto a las motivaciones para hacer el viaje, se comprueba la manifestación de una mayor motivación religiosa en la asistencia a las procesiones de Semana Santa, donde se conmemora la pasión, muerte y resurrección de Jesucristo, en un ambiente sobrio y de recogimiento (un 63,4\% tiene motivaciones exclusivamente religiosas y un 34,3\% mezcla las motivaciones religiosas con motivaciones de otro tipo; tan sólo un 2,3\% no tiene motivaciones relacionadas con la fe). Por el contrario, en la peregrinación de la romería en honor a la Virgen del Rocío, de carácter alegre y festivo, es donde se manifiesta un mayor porcentaje de motivaciones no religiosas (un $17,1 \%$ ), muchas de ellas de ocio y sociales. Respecto a la peregrinación dedicada al Apóstol Santiago, en la mayoría de los casos $(50,8 \%)$ se mezclan las motivaciones religiosas con motivaciones de otro tipo (culturales, sociales, deportivas,...). Tan sólo un 8,6\% afirma no tener motivaciones relacionadas con la fe.

Por último es interesante mencionar las diferencias de satisfacción con respecto a la infraestructura hotelera. La mayoría de los peregrinos a Santiago de Compostela $(54,8 \%)$ y de los turistas de Sevilla en la Semana Santa (un 53,3\%) se muestran insatisfechos con las instalaciones. En el primer caso se debe al mal estado de conservación y limpieza de algunos albergues, pero sobre todo a la escasez de los mismos. En el segundo caso las razones se centran en el precio tan elevado que alcanzan los alojamientos en esta ciudad durante el periodo de Semana Santa, disminuyendo así durante esos días la relación calidad-precio.

A fin de identificar más diferencias y semejanzas entre los tres perfiles de visitantes, se realizó un análisis bivariante para determinar asociaciones significativas entre las variables. En primer lugar se analizó para cada perfil la relación de la motivación del viaje con el resto de variables (Tabla 4), detectándose que tan sólo existe una asociación común en ellos. En los tres casos la motivación se asocia con la repetición del viaje. A medida que el motivo del viaje es religioso la persona que lo realiza repetiría la experiencia, mientras que si la motivación no es religiosa sino de otro tipo (por ejemplo, cultural) no repetiría, pues al haber conocido ya el lugar, en su próximo viaje prefiere visitar un lugar diferente.

Tabla 4

ANÁLISIS BIVARIANTE DE LA MOTIVACIÓN DEL VIAJE CON EL RESTO DE VARIABLES

\begin{tabular}{|l|l|c|c|c|}
\hline & \multicolumn{1}{|c|}{ Variables asociadas } & $\chi^{2}$ & $\mathrm{gl}$ & Prob. \\
\hline \multirow{3}{*}{ Camino de Santiago } & Repetición del viaje / Motivación & 20,2 & 2 & 0 \\
\cline { 2 - 5 } & Edad / Motivación & 32,4 & 8 & 0 \\
\cline { 2 - 5 } & Con quién realizó el viaje / Motivación & 17,2 & 6 & 0,007 \\
\hline \multirow{2}{*}{ Romería del Rocío } & Repetición del viaje / Motivación & 15,4 & 2 & 0,008 \\
\cline { 2 - 5 } & Renta / Motivación & 58,9 & 8 & 0 \\
\hline \multirow{2}{*}{ Semana Santa de Sevilla } & Repetición del viaje / Motivación & 15,4 & 2 & 0,008 \\
\cline { 2 - 5 } & Renta / Motivación & 42,3 & 8 & 0 \\
\hline
\end{tabular}

Fuente: Elaboración propia.

Nota: $\chi^{2}$ Estadístico Chi-cuadrado. Variables relacionadas para $\alpha=0,05 . \mathrm{gl}=$ grados de libertad.

Respecto a las diferencias entre los perfiles, se observa que en el Camino de Santiago la motivación está relacionada con la edad y con la compañía durante el viaje. Por una parte, a más edad el visitante tiene una motivación religiosa mayor. Y por otra parte, el visitante que 
está más motivado religiosamente realiza el viaje solo, quizás porque cuando se busca un reencuentro personal y con Dios no se necesita de la compañía de terceras personas. Por el contario, en el turista de la Romería del Rocío y de la Semana Santa de Sevilla se manifiesta una asociación entre la motivación y la renta. A mayor nivel de renta la motivación es menos religiosa y por tanto de otro tipo, como por ejemplo social o cultural.

En segundo lugar se exploró la relación de la satisfacción experimentada en el viaje con el resto de variables (Tabla 5). Esta satisfacción abarca desde la organización del viaje, la realización del mismo -medios de transporte, alojamientos, señalización, servicio de atención al público- y el cumplimiento de las expectativas. En este análisis se detectaron dos asociaciones significativas en los tres perfiles. En los tres casos la satisfacción se asocia con la motivación y con la satisfacción sobre la infraestructura hotelera. Por un lado, las personas más satisfechas son las que realizan el viaje exclusivamente por motivos religiosos.

Y, por otro lado, la insatisfacción del viaje es debido principalmente a un servicio de alojamiento inadecuado o escaso (hostelería). Como se ha comentado antes, en el caso del Camino de Santiago por la escasez de albergues y en el caso de la Semana Santa de Sevilla por el alto precio de los alojamientos. En el caso de la romería del Rocío se debe principalmente al precio, pero también a la escasez de alojamientos durante los días en que se celebra este evento religioso.

Tabla 5

ANÁLISIS BIVARIANTE DE LA SATISFACCIÓN EXPERIMENTADA EN EL VIAJE CON EL RESTO DE VARIABLES

\begin{tabular}{|l|l|c|c|c|}
\hline & \multicolumn{1}{|c|}{ Variables asociadas } & $\chi^{2}$ & $\mathrm{gl}$ & Prob. \\
\hline \multirow{5}{*}{ Camino de Santiago } & Motivación / Satisfacción & 21,7 & 4 & 0 \\
\cline { 2 - 5 } & Infraestructura hotelera / Satisfacción & 36,7 & 2 & 0 \\
\cline { 2 - 5 } & Género / Satisfacción & 11,6 & 2 & 0,007 \\
\cline { 2 - 5 } & Lugar de procedencia / Satisfacción & 19,3 & 4 & 0 \\
\hline \multirow{4}{*}{ Romería del Rocío } & Motivación / Satisfacción & 23,8 & 4 & 0 \\
\cline { 2 - 5 } & Infraestructura hotelera / Satisfacción & 32,6 & 2 & 0 \\
\cline { 2 - 5 } & Renta / Satisfacción & 24,8 & 8 & 0 \\
\hline \multirow{3}{*}{ Semana Santa de Sevilla } & Motivación / Satisfacción & 18,6 & 4 & 0,006 \\
\cline { 2 - 5 } & Infraestructura hotelera / Satisfacción & 52,5 & 2 & 0 \\
\cline { 2 - 5 } & Renta / Satisfacción & 25,9 & 8 & 0 \\
\hline
\end{tabular}

Fuente: elaboración propia.

Nota: $\chi^{2}$ Estadístico Chi-cuadrado. Variables relacionadas para $\alpha=0,05 . \mathrm{gl}=$ grados de libertad.

Como diferencias entre los perfiles, se detectaron las siguientes:

- En el Camino la satisfacción está asociada con el lugar de precedencia (aquellos que provienen de otros países están más satisfechos con el Camino) y con el género (los hombres puntuaron más alto que las mujeres la valoración de la experiencia). Este resultado viene a confirmar las diferencias de género consideradas por autores como Rinschede (1992). No obstante, autores como Shuo et al. (2009) encontraron que eran 
las mujeres quienes evaluaban de forma significativamente más alta que los hombres sus experiencias en la visita al templo de la Madre Santa Da-Lin, un templo taoísta localizado en Taiwán.

- En la Semana Santa la satisfacción está relacionada con la renta (a mayor nivel de renta el grado de satisfacción es más elevado, debido principalmente a que el visitante al tener un poder adquisitivo más alto se aloja en mejores hoteles, come en mejores restaurantes y no se fija tanto en el precio, valorando más la calidad del servicio prestado). En la romería del Rocío ocurre lo mismo. Es decir, cuando el visitante tiene mayor poder adquisitivo realiza la romería utilizando mejores enseres y consumiendo mejores servicios, valorando más la calidad que el precio.

En tercer lugar se analizó la relación entre las variables socioeconómicas y las características del viaje, no detectándose ninguna asociación común entre los perfiles (Tabla 6). En concreto, en el Camino de Santiago no se detectó ninguna relación significativa, mientras que en la Semana Santa y en la romería del Rocío se detectaron dos. La primera, la asociación entre el gasto medio diario del viaje y su duración. A medida que el visitante pernocta más días, su gasto medio diario es mayor, principalmente en alojamiento y restauración, y en menor proporción en souvenirs. Y la segunda, la relación del nivel de renta con el gasto medio diario. Se pone de manifiesto que a medida que el poder adquisitivo del visitante es mayor el gasto medio es más elevado puesto que escoge servicios de mayor calidad.

Tabla 6

ANÁLISIS BIVARIANTE DE LAS CARACTERÍSTICAS DEL VIAJE CON EL RESTO DE VARIABLES

\begin{tabular}{|l|l|c|c|c|}
\hline & \multicolumn{1}{|c|}{ Variables asociadas } & $\chi^{2}$ & gl & Prob. \\
\hline Camino de Santiago & -- & & & \\
\hline \multirow{2}{*}{ Romería del Rocío } & Gasto medio / duración del viaje & 56,9 & 9 & 0 \\
\cline { 2 - 6 } & Nivel de renta / gasto medio & 44,7 & 12 & 0 \\
\hline \multirow{2}{*}{ Semana Santa de Sevilla } & Gasto medio / duración del viaje & 40,3 & 9 & 0 \\
\cline { 2 - 6 } & Nivel de renta / gasto medio & 38,7 & 12 & 0 \\
\hline
\end{tabular}

Fuente: elaboración propia.

Nota: $\chi 2$ Estadístico Chi-cuadrado. Variables relacionadas para $\alpha=0,05 . \mathrm{gl}=$ grados de libertad.

\section{CONCLUSIONES}

En la actualidad, el turismo en destinos y eventos religiosos está creciendo en todo el mundo, convirtiéndose en un motor de desarrollo para muchas zonas. Los caminos de peregrinación y los itinerarios religiosos se han convertido en productos turísticos que permiten una ordenación del territorio e inciden significativamente en el conjunto de las comunidades por las que cruzan. No obstante, la falta de estadísticas e información cualitativa y cuantitativa sobre la demanda, que permitirían una mejor gestión del patrimonio religioso, sigue siendo aún un reto (Lanquar, 2008; Triantafillidou et al., 2010). La pregunta es, ¿cómo son 
estos turistas religiosos en diferentes zonas geográficas de España? ¿Existen semejanzas entre ellos en las diferentes peregrinaciones y eventos sagrados, o son totalmente diferentes en función de las características de cada destino?

Los resultados de este artículo apoyan las sugerencias de Nolan y Nolan (1992) de que diferentes categorías de destinos religiosos atraen a diferentes tipos de visitantes, en busca de experiencias distintas.

El articulo presenta un estudio comparativo del perfil del turista en tres de las manifestaciones religiosas más relevantes de España (el Camino de Santiago, la Romería de la Virgen del Rocío y la Semana Santa de Sevilla), analizando sus características, comportamientos, motivaciones y niveles de satisfacción. Según los resultados, hay diferencias y similitudes entre ellos. Las principales diferencias, que se explican principalmente por las características particulares de cada peregrinación o evento, se detectan en el estado civil, nivel de ingresos, el gasto medio diario, la compañía durante el viaje, su duración, la motivación y la satisfacción con los servicios de alojamiento.

En general, el Camino de Santiago es un viaje con un contexto más propicio para reencontrarse individualmente con la fe, y además es más accesible a personas de renta más baja porque, a pesar de que el viaje tiene una duración mayor, el gasto necesario para hacer la peregrinación no es muy elevado (un 75,6\% de los visitantes no gastan más de 35 euros/día). Y, en consonancia con las afirmaciones de Lois y Santos (2015), la mayoría de las personas que realizan el Camino (un 50,8\%) mezclan motivaciones religiosas o espirituales con motivaciones turísticas.

La Romería del Rocío y la Semana Santa son manifestaciones de religiosidad popular organizadas dentro de hermandades, donde los hermanos celebran el evento en una ambiente familiar y de amistad. En el caso de la Romería, esta cuenta con un ambiente alegre y festivo, y aunque el viaje suele ser más corto que en el Camino de Santiago, no es tan accesible a las personas de menor renta, en gran parte debido a los altos costes en los que se incurre para preparar la peregrinación (un 67,1\% de los visitantes gastan más de 75 euros/ día). Quizás por su carácter festivo, es donde se manifiesta un mayor porcentaje de motivaciones no religiosas (un 17,1\% no acude motivado por la fe). En la Semana Santa de Sevilla, donde se conmemora la pasión, muerte y resurrección de Jesucristo en un ambiente sobrio y de recogimiento, es donde se manifiesta una mayor motivación religiosa (tan sólo un 2,3\% acude por otras motivaciones). En el caso de Sevilla, también puede decirse que en esta época es menos accesible a las clases sociales más bajas, principalmente porque los hoteles suelen elevar sus precios en estas fechas (un 46,2\% de los visitantes tienen un gasto medio superior a 75 euros/ día). Esto propicia que la duración del viaje sea menor.

Como semejanzas entre los tres perfiles se comprueba que los turistas con mayor motivación religiosa muestran más satisfacción con el viaje y son más fieles a los destinos. Esto es consistente con las aportaciones de Fleischer (2000) y Shuo et al. (2009). Fleischer (2000), que analiza una muestra de turistas a Tierra Santa compuesta principalmente por cristianos católicos y protestantes, señala que aquellos que acuden a la región motivados por la religión obtienen un mayor nivel de satisfacción que los turistas que acuden por otras motivaciones, sobre todo los peregrinos cristianos de carácter católico. Y, en consonancia, Shuo el al. (2009) muestran que los turistas movidos por la fe son más fieles a los destinos. Desde una perspectiva práctica de gestión, como la motivación religiosa es un 
determinante importante de la repetición de la visita, los datos sobre el volumen de adherentes firmes dentro de una población podrían ser útiles como un indicador del número de visitantes potenciales. Una consecuencia adicional es que la gestión de los visitantes, incluso el más devoto, requerirá actividades que tengan algún carácter recreativo, como ir a restaurantes, realizar compras, ...

Otra similitud entre los perfiles es que la no satisfacción con el viaje se asocia a la insatisfacción con la infraestructura hotelera. En este sentido, Kresić et al. (2013), al analizar la satisfacción del turista en el contexto de peregrinación de Medjugorje, identifican que las instalaciones de alojamiento y restauración son atributos híbridos a los que se les debe asignar una prioridad más alta en las estrategias para mejorar la experiencia turística global. Estos atributos contribuyen a la experiencia global a un ratio más o menos constante; es decir, un aumento / disminución en el rendimiento para estos atributos del destino (según la percepción de los turistas) produce un aumento / descenso proporcional en el nivel de satisfacción global del turista.

Por tanto, hay que dedicar los recursos y esfuerzos necesarios para asegurar que los servicios de alojamiento se gestionen correctamente en cada destino. Entender las variables que determinan la insatisfacción turística es extremadamente importante, sobre todo en un contexto altamente competitivo con turistas informados y exigentes. La identificación de esta clase de variables es muy útil en la dirección de la planificación de marketing para un destino.

La globalización ha abierto al turismo religioso a un proceso de comercialización transformándolo en un producto comercial que no era el de sus orígenes. Por tanto, las entidades que deseen promover las visitas a destinos sagrados deben diseñar planes de marketing más eficaces. Además, como los viajes por motivos religiosos están en aumento, al ser un turismo con un alto grado de fidelización, el diseño de un plan de marketing adecuado al destino puede ayudar a desarrollar e incrementar el mercado de este tipo segmento turístico, en consonancia con un plan estratégico de desarrollo sostenible de ámbito local donde todos los stakeholder se vean implicados.

Como todos los estudios, esta investigación tiene algunas limitaciones. La principal limitación se centra en que los datos recogidos han sido obtenidos a partir de muestras de visitantes durante un determinado periodo de tiempo (el año 2008). Así, como futura línea de investigación se recomienda un estudio con una visión más diacrónica, puesto que las características de los turistas evolucionan dentro de un contexto general relativo al turismo religioso y a la actividad turística.

\section{BIBLIOGRAFÍA}

AMBRÓSIO, V. y PEREIRA, M. (2007): «Case study 2: Christian/Catholic pilgrimage studies and analices», en R. Raj y N.D. Morphet (Eds.), Religious tourism and pilgrimage festivals management. Wallingford, CABI, pp. 140-152.

ANDRES, J.L. y ESPEJO, C. (2006): «Interacción mito religioso / producto turístico en la imagen de la ciudad: Caravaca de la Cruz (Murcia)», Cuadernos de Turismo, $\mathrm{n}^{\circ}$ 18, pp. 7-61.

ANSOFF, I. (1988): The new corporate strategy. New York, Wiley. 
ARREGUI, J.A. (2009): «El turismo religioso como dinamizador sostenible del territorio: el caso de Torreciudad», II Congreso Internacional de Turismo Sostenible en Montaña. Huesca. Universidad de Zaragoza. Disponible en http://www.unizar.es/centros/eueeh/ master/ARREGUI.pdf

AYUNTAMIENTO DE ALMONTE (2012): Año Jubilar Mariano El Rocío. Plan director. España, Ayuntamiento de Almonte.

BAR, D. y COHEN-HATTAB, K. (2003): «A new kind of pilgrimage: the modern tourist pilgrim of ninetieth century and early twentieth century Palestine», Middle Eastern Studies, $\mathrm{n}^{\mathrm{o}} 32(2)$, pp. 131-48.

BIDECI, M. y ALBAYRAK, T. (2016): «Motivations of the Russian and German tourists visiting pilgrimage site of Saint Nicholas Church», Tourism Management Perspectives, $\mathrm{n}^{\circ}$ 18(April), pp. 10-13,

CÁMARA DE COMERCIO DE SEVILLA (2010): El impacto de la celebración de la Semana Santa sobre la ciudad de Sevilla. Sevilla, Confederación de Empresarios de Sevilla.

CANOVES, G. (2006): «Turismo religioso en Monserrat: montaña de fe, montaña de turismo», Cuadernos de Turismo, $\mathrm{n}^{\circ}$ 18, pp. 63-76.

CANOVES, G. y BLANCO, A. (2011): «Turismo religioso en España: ¿la gallina de los huevos de oro? Una vieja tradición, versus un turismo emergente», Cuadernos de Turismo, $\mathrm{n}^{\mathrm{o}} 27$, pp. 115-131.

CENTRO DE INVESTIGACIONES SOCIOLÓGICAS (2013): Barómetro de julio, estudio $\mathrm{n}^{\circ}$ 2.993. Disponible en http://www.cis.es/cis/export/sites/default/-Archivos/Marginales/2980_2999/2993/Es2993.pdf

CLARKE, A. y RAFFAY, Á. (2015): «Religion, Local Produce and Sustainability at Religious Sites in Hungary», International Journal of Religious Tourism and Pilgrimage, $\mathrm{n}^{\circ}$ 3(2), pp. 33-47.

COHEN, E. (1979): «A phenomenology of tourist experiences», Sociology, $\mathrm{n}^{\circ}$ 13(2), pp. 179-201.

COHEN, E. (1992): «Pilgrimage Centers: Concentric and Excentric», Annals of Tourism Research, $\mathrm{n}^{\mathrm{o}}$ 19(1), pp. 33-50.

COLLINS-KREINER, N. (2010): «Researching Pilgrimage: Continuity and transformations», Annals of Tourism Research, $\mathrm{n}^{\circ}$ 37(2), pp. 440-456.

COLLINS-KREINER, N. y GATRELL, J. (2006): «Tourism, heritage and pilgrimage: the case of Haifa's Baháí gardens», Journal of Heritage Tourism, n 1(1), pp. 32-50.

COLLINS-KREINER, N. y KLIOT, N. (2000): «Pilgrimage Tourism in the Holy Land: The Behavioural Characteristics of Christian Pilgrims», GeoJournal, n 501, pp. 55-67.

COVELL, S.G. (2005): Japanese Temple Buddhism: Worldliness in a Religion of Renunciation. Honolulu, University of Hawaii Press.

DAVIE, G. (2007): «Vicarious religion: a methodological challenge», en N. T. Ammerman (Ed.), Everyday religion: Observing modern religious lives. New York, Oxford University Press, pp. 21-37.

DIGANCE, J. (2003): «Pilgrimage at contested sites», Annals of Tourism Research, $n^{o} 30(1)$, pp. 143-159. 
DAHLBERG, A. (1991): «The Body as a Principle of Holism: Three Pilgrimages to Lourdes», en J. Eade y M. Sallnow (Eds.), Contesting the Sacred: The Anthropology of Christian Pilgrimage. London, Routledge, pp. 30-50.

EADE, J. (1992): «Pilgrimage and Tourism at Lourdes, France», Annals of Tourism Research, $\mathrm{n}^{\mathrm{o}} 19(1), \mathrm{pp} .18-32$.

FLEISCHER, A. (2000): «The Tourist Behind the Pilgrim in the Holy Land», International Journal of Hospitality Management, $\mathrm{n}^{\circ}$ 19, pp. 311-326.

GRABURN, N. (1977): «Tourism: The Sacred Journey», en V. L. Smith (ed.), Hosts and Guests: The Anthropology of Tourism. Philadelphia, University of Pennsylvania Press, pp. 17-31.

GALLUP (2009): Religion Provides Emotional Boost to World's Poor. Disponible en http:// www.gallup.com/poll/116449/religion-provides-emotional-boost-world-poor.aspx

GETZ, D. (1986): «Models in tourism planning. Towards integration of theory and practice», Tourism Management, $\mathrm{n}^{\circ}$ 7, pp. 21-32.

GIL DE ARRIBA, C. (2006): «Turismo religioso y el valor sagrado de los lugares: simbología identitaria y patrimonialización del monasterio de Santo Toribio de Liébana (Cantabria)», Cuadernos de Turismo, $\mathrm{n}^{\circ} 18, \mathrm{pp} .77-102$.

HALL, C. (2000): Tourism planning. Policies, processes and relationships. Essex, Prentice Hall.

HARRIS, R. (1999): Lourdes: Body and Spirit in the Secular Age. London, Allen Lane.

HARVEY, D. (2003): «Cell Church: its Situation in British Evangelical Culture», Journal of Contemporary Religion, $\mathrm{n}^{\circ}$ 18(1), pp. 95-109.

IRIMIAS, A., MITEV, A. y MICHALKO, G (2016): «Demographic Characteristics Influencing Religious Tourism Behaviour: Evidence form a Central-Eastern-European country», International Journal of Religious Tourism and Pilgrimage, $\mathrm{n}^{\circ} 4$ (4), Article 3.

IVARS, J. (2004): «Regional planning in Spain», Annals of Tourism Research, $\mathrm{n}^{\circ}$ 31(2), pp. $313-333$.

JIMÉNEZ, C. (2008): «Devotos y espectadores: rezar y hacer turismo», en E. Díaz \& J. Hernández (Eds.), Patrimonio cultural, turismo y religión. México, DF, Escuela Nacional de Antropología e Historia, pp. 147-161.

KRESIĆ, D., MIKULIĆ, J. y MILICEVIĆ, K. (2013): «The Factor Structure of Tourist Satisfaction at Pilgrimage Destinations: the Case of Medjugorje», International Journal of Tourism Research, $\mathrm{n}^{\circ}$ 15, pp. 484-494.

LANQUAR, R. (2008): «Tourism and Religions: A Contribution to the Dialogue among Religions, Cultures and Civilizations - Summary of the Report Prepared in the Context of the Conference». En International Conference on Tourism, Religions and Dialogue of Cultures; Cordoba, Spain, 29-31 October 2007. Madrid, World Tourism Organization, pp. 197-204.

LOIS, R. y SANTOS, X. (2015): «Tourists and pilgrims on their way to Santiago. Motives, Caminos and final destinations», Journal of Tourism and Cultural Change, $\mathrm{n}^{\circ} 13(2)$, pp. 149-164.

MARGRY, P. (2008): Shrines and Pilgrimage in the Modern World: New Itineraries into the Sacred. Amsterdam, University of Amsterdam Press. 
MACCANNELL, D. (1973): «Staged Authenticity: Arrangements of Social Space in Tourist Settings», American Journal of Sociology, $\mathrm{n}^{\circ}$ 793, pp. 589-603.

McINTOSH, A. y ZAHRA, A. (2013): «World Youth Day: contemporary pilgrimage and tourism». Paper presented at The International Conference on Tourism (ICOT) 2013, Larnaca, Cyprus.

MILLÁN, G., PÉREZ, L. y MARTÍNEZ, R. (2012): «Etapas del ciclo de vida en el desarrollo del turismo religioso: una comparación de estudios de caso», Cuadernos de Turismo, $\mathrm{n}^{\circ} 30$, pp. 241-266.

MILLÁN, G., PÉREZ, L. y MORALES, E. (2010): «Turismo Religioso en el Camino de Santiago», Revista de Economía, Sociedad, Turismo y Medio Ambiente, $\mathrm{n}^{\circ}$ 10, pp. 75-96.

NILSSON, M. y TESFAHUNEY, M. (2016): «Performing the "post-secular" in Santiago de Compostela», Annals of Tourism Research, $\mathrm{n}^{\circ}$ 57, pp. 18-30.

NYAUPANE, G.P. y BUDRUK, M. (2009): «South Asian heritage tourism: conflict, colonialism, and cooperation», en D. J. Timothy \& G. P. Nyaupane (Eds.), Cultural heritage and tourism in the developing world: A regional perspective. London, Routledge, pp. 127-145.

NOLAN, M. y NOLAN, S. (1992): «Religious sites as tourism attractions in Europe», Annals of Tourism Research, $\mathrm{n}^{\circ}$ 19(1), pp. 68-78.

OFICINA DE ACOGIDA DEL PEREGRINO (2015): La peregrinación a Santiago. Estadísticas. Santiago de Compostela, Arzobispado de Santiago de Compostela.

OLSEN, D.H. (2006): «Management issues for religious heritage attractions», en D. J. Timothy \& D. H. Olsen (Eds.), Tourism, Religion \& Spiritual Journeys. Great Britain, Routledge.

OLSEN, D.H. (2010): «Pilgrims, tourists and Max Weber's ideal types», Annals of Tourism Research, $\mathrm{n}^{\mathrm{o}}$ 37(3). Amsterdam, Holanda, pp. 848-851.

OLSEN, D.H. y TIMOTHY, D.J. (2006): «Tourism and religious journeys», en D. J. Timothy \& D. H. Olsen (Eds.), Tourism, Religion and Spiritual Journeys. London, Routledge, pp. 1-23.

ORGANIZACIÓN MUNDIAL DEL TURISMO (2008): International Conference on Tourism, Religions and Dialogue of Cultures; Cordoba, Spain, 29-31 October 2007. Madrid, World Tourism Organization.

PARGAMENT, K. (1999): «The Psychology of Religion and Spirituality? Yes and no», International Journal for the Psychology of Religion, ${ }^{\circ}$ 9, pp. 3-16.

PORCAL, M.C. (2006): «Turismo cultural, turismo religioso y peregrinaciones en Navarra. Las Javieradas como caso de estudio», Cuadernos de Turismo, nº 18, pp. 103-134.

PORTER, M. (1982): Estrategia Competitiva. Técnicas para el Análisis de los Sectores Industriales y de la Competencia. México, CECSA.

READER, I. (2007): «Pilgrimage Growth in the Modern World: Meanings and Implications», Religion, $\mathrm{n}^{\circ} 37$, pp. 210-229.

REVISTA IBÉRICA (2015): Fiestas de Interés Turístico Nacional. Disponible en: http:// www.revistaiberica.com/fiestas/interes_turistico2.htm

RINSCHEDE, G. (1992): «Forms of religious tourism», Annals of Tourism Research, $\mathrm{n}^{\circ} 19$, pp. 51-67. 
ROBLES, J. (2001): «Turismo religioso. Alternativa de apoyo a la preservación del patrimonio y desarrollo», Biblio 3 W. Revista Bibliográfica de Geografía y Ciencias Sociales, $\mathrm{n}^{\circ}$ 316.

RUTAS POR ESPAÑA (2015): Fiestas de Interés Turístico Internacional. Disponible en http://www.rutasporespana.es/rutasEspanya/html/ListaFiestasInt.php

SANCTUAIRES NOTRE-DAME DE LOURDES (2012): Donativos y legados. Disponible en http://es.lourdes-france.org

SANTOS, M.G.M.P. (2003): «Religious tourism: contributions towards a clarification of concepts», en C. Fernandes; F. McGettigan y J. Edwards (Eds.), Religious tourism and pilgrimage. ATLAS Special Interest Group, 1st Expert Meeting, Fátima, Portugal, Tourism Board of Leiria/Fatima.

SANTOS, X. M. (2006): «El Camino de Santiago: Turistas y peregrinos hacia Compostela», Cuadernos de Turismo, ${ }^{\circ}$ 18, pp. 135-150.

SHACKLEY, M. (2001a): Managing sacred sites: service provision and visitor experience. London, Continuum.

SHACKLEY, M. (2001b): «Sacred World Heritage Sites: balancing meaning with Management», Tourism Recreation Research, no 26(1), pp. 5-10.

SHACKLEY, M. (2008): «Management challenges for religion-based attractions», en A. Fyall; A. Leask; B. Garrod y S. Wanhill (Eds.), Managing Visitor Attractions, 2nd edition. Butterworth Heinemann, Oxford.

SHARPLEY, R (2009): «Tourism, religion and spirituality», en T. Jamal y M. Robinson (Eds.), The Sage Handbook of Tourism Studies. London, Sage, pp. 237-253.

SHARPLEY, R. y SUNDARAM, P. (2005): «Tourism: a sacred journey? The case of Ashram tourism, India», International Journal of Tourism Research, $\mathrm{n}^{\circ}$ 7(3), pp. 161-171.

SHUO, Y.S., RYAN, C. y LIU, G. (2009): «Taoism, temples and tourists: The case of Mazu pilgrimage tourism», Tourism Management, $\mathrm{n}^{\circ} 30$, pp. 581-588.

SMITH, V. L. (1989): Hosts and Guests - The anthropology of tourism. Pennsylvania, University of Pennsylvania Press.

SMITH, V. L. (1992): «Introduction. The quest in guest», Annals of Tourism Research, $\mathrm{n}^{\circ}$ 19(1), pp. 1-17.

SWANSON, K. y TIMOTHY, D. (2012): «Souvenirs: icons of meaning, commercialization and commoditization», Tourism Management, $\mathrm{n}^{\circ} 33(3)$, pp. 489-499.

DE SOUSA, D. (1993): «Tourism and pilgrimage: tourists as pilgrims?», Contours, $\mathrm{n}^{\circ}$ 6(2), pp. 4-8.

STARK, R., HAMBERG, E. y MILLER, A. (2005): «Exploring Spirituality and Unchurched Religions in America, Sweden and Japan», Journal of Contemporary Religion, ${ }^{\circ} 20$, pp. 3-23.

TILSON, D.J. (2005): «Religious-spiritual tourism and promotional campaigning: A church state partnership for St. James and Spain», Journal of Hospitality, Marketing \& Management, $\mathrm{n}^{\mathrm{o}}$ 12(1-2), pp. 9-40.

TRIANTAFILLIDOU, A., KORITOS, C., CHATZIPANAGIOTOU, K. y VASSILIKOPOULOU, A. (2010): «Pilgrimages: the "promised land" for travel agents?», International Journal of Contemporary Hospitality Management, $\mathrm{n}^{\mathrm{o}}$ 22(3), pp. 382-398. 
VILA, M., COSTA, C. y ROVIRA, X. (2010): «The creation and use of scorecards in tourism planning: A Spanish example», Tourism Management, $\mathrm{n}^{\circ}$ 31(2), pp. 232-239.

VILLA, A. (2006): «El Rocío y el turismo de peregrinación», Cuadernos de Turismo, $\mathrm{n}^{\circ} 18$, pp. 151-174.

VUKONIC, B. (1992): «Medjugorje's religion and tourism connection», Annals of Tourism Research, $\mathrm{n}^{\circ}$ 19(1), pp. 79-91.

WILLSON, G., MCINTOSH, A. y ZAHRA, A. (2013): «Tourism and spirituality: A phenomenological analysis», Annals of Tourism Research, $\mathrm{n}^{\circ}$ 42, July 2013, pp. 150-168.

WORLD RELIGIOUS TRAVEL ASSOCIATION (2010): What is WRTA? Lexington, KY. World Religious Travel Association. 